Polymer Journal, Vol. 39, No. 8, pp. 861-873 (2007)

(C) 2007 The Society of Polymer Science, Japan

\title{
Synthesis of A Main Chain-Type Polyrotaxane Consisting of Poly(crown ether) and sec-Ammonium Salt Axle and Its Application to Polyrotaxane Network
}

\author{
Yasuhiro KoHSAKA, Gen-ichi KonISHI, and Toshikazu TAKATA ${ }^{\dagger}$ \\ Department of Organic and Polymeric Materials, Tokyo Institute of Technology, \\ 2-12-1, Ookayama, Meguro-ku, Tokyo 152-8552, Japan
}

(Received May 1, 2007; Accepted May 18, 2007; Published July 3, 2007)

\begin{abstract}
According to the molecular design, a main chain-type polyrotaxane (B) was synthesized by the initial threading of sec-ammonium axle $\mathbf{5}$ into poly(crown ether) $\mathbf{3}$ to polypseudorotaxane $\mathbf{7}$ followed by end-capping of the axle terminal with a bulky aromatic isocyanate. The pseudorotaxane formation using poly(crown ether) $\mathbf{3}$ was studied in detail from viewpoints of effects of solvent, temperature, concentration, feed ratio, and so on. The complete pseudorotaxanation ( $>99 \%$ ) was achieved, while the incorporation ratio of the axle moiety was finely controllable, by changing the feed ratio of $\mathbf{3}$ and $\mathbf{5}$. The corresponding polyrotaxane $\mathbf{8}$ was obtained in a high yield and in a high rotaxanated ratio by the end-capping of $\mathbf{7}$ with 3,5-dimethylphenyl isocyanate. $N$-Acetylation of $\mathbf{8}$ with acetic anhydride afforded neutral polyrotaxane $\mathbf{9}$ of which molecular weights could be estimated by GPC. Polypseudorotaxane 7 was utilized for the preparation of a new type of polyrotaxane network: the reaction of $\mathbf{7}$ with 4,4'-methylenebis(phenyl isocyanate) (MDI) which combined terminal OH group of the axle of $\mathbf{7}$ yielded a gelled materials $\mathbf{1 0}$. The gel was swollen in polar solvents such as dimethyl sulfoxide (DMSO, 9800\%) to give transparent material. ${ }^{1} \mathrm{H}$ NMR spectrum of $\mathbf{1 0}$ indicated the formation of the rotaxane structure as crosslinking point, although the degree of crosslink was low.

[doi:10.1295/polymj.PJ2007030]

KEY WORDS Polyrotaxane / Polyrotaxane Network / Poly(crown ether) / sec-Ammonium Salt /

Polymer Reaction / Synthesis /
\end{abstract}

Since Harada et al. reported the synthesis of cyclodextrin-based main chain type polyrotaxanes, ${ }^{1}$ a variety of polyrotaxanes have been prepared so far. ${ }^{2}$ As shown in Figure 1, several kinds of polyrotaxane skeletons are known, i.e., main chain-type ones (A and B) ${ }^{3}$ side chain-type ones $(\mathrm{C}$ and $\mathrm{D}),{ }^{4}$ daizy-chain type one (E), poly[3]rotaxane (F), and so on. ${ }^{5-7}$ Harada et al. prepared the main chain-type polyrotaxanes (A) consisting of both cyclodextrins (CDs) and linear polymers such as poly(ethylene glycol) (PEG) and poly(propylene glycol) (PPG). ${ }^{1}$ We have recently found a facile synthetic method of CD-based main chain-type polyrotaxane (A) by one pot reaction in water ${ }^{8}$ or by grinding without solvent. ${ }^{3 \mathrm{~g}, \mathrm{~h}} \mathrm{~A}$ few applications of such main chain-type polyrotaxanes (A) have been examined, e.g. thermo-responsive polyrotaxane composed of highly methylated $\alpha$-CD and PEG by Kataoka et $a l .{ }^{9}$ and CD-based polyrotaxane networks by crosslinking of polyrotaxanes by Ito et al. ${ }^{10-12}$ On the other hand, main chain-type polyrotaxane (B), polyrotaxane having the wheel components as the repeating units of a linear polymer and the axle components threading into the wheel placed on the linear polymer, was an interesting unknown polyrotaxane. The axle units are spatially independent from the main chain to act as 'mobile bearing groups'. Crown ether and sec-ammonium salt couple is another useful combination to pre- pare rotaxane and polyrotaxane. ${ }^{2}$ Gibson et al. reported a main chain-type polypseudorotaxane like the polyrotaxane (B) prepared as a complex between poly(crown ether) and bipyridinium dication, which showed a high pseudorotaxanation ratio. ${ }^{13}$ Further, Gibson et al. prepared a similar main chain-type polypseudorotaxane as an intermediate which was eventually converted to a polyrotaxane network. ${ }^{14}$ We have synthesized a polyrotaxane network possessing a fundamental polyrotaxane structure like B by using poly(crown ether) and dumbbell-shaped sec-ammonium salt having a dynamic covalent bond. ${ }^{15,16}$ However, there has been no study on the main chain-type polyrotaxane (B) so far, in contrast to a lot of reports on the main chain-type polyrotaxane (A) as mentioned above. Hence, the establishment of efficient and convenient synthetic procedure for the main chain-type polyrotaxane (B) is of great significance. In our previous work, ${ }^{17}$ we have preliminarily disclosed the preparation of a main chain-type polyrotaxane (B) composed of poly(crown ether) and sec-ammonium salt axle. This paper describes the details of the preparation of main chain-type polyrotaxane (B) according to the polymerization-rotaxanation protocol, along with the derivation of it to polyrotaxane network by applying the polymerization-rotaxanation protocol.

${ }^{\dagger}$ To whom correspondence should be addressed (E-mail: takata.t.ab@m.titech.ac.jp). 


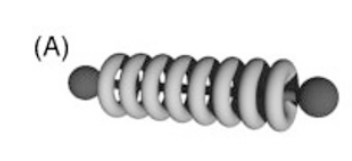

(D)

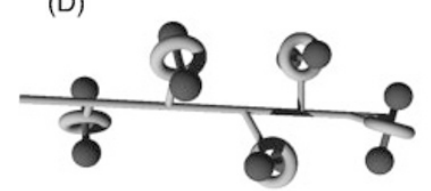

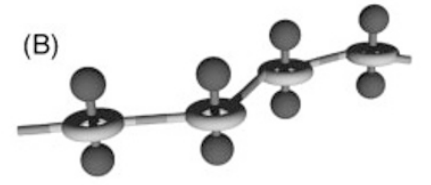

(E)

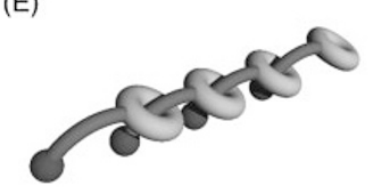

(C)

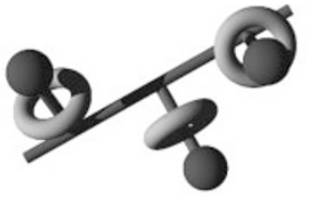

(F)

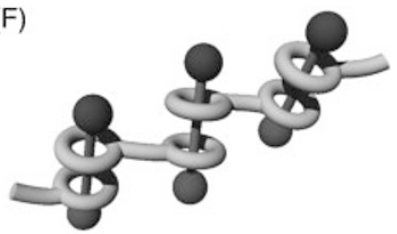

Figure 1. Illustration of several types of polyrotaxanes. (A), (B) main chain-types, (C), (D) side chain-types, (E) daisy-chain type, and (F) poly[3]rotaxane.

\section{EXPERIMENTAL}

\section{General}

${ }^{1} \mathrm{H}(400 \mathrm{MHz})$ and ${ }^{13} \mathrm{C}(100 \mathrm{MHz})$ NMR spectra were recorded on a JEOL GTX-400 spectrometer using $\mathrm{CDCl}_{3}$ as the solvent and tetramethylsilane as the internal standard. Molecular weight and its distribution were measured by gel permeation chromatography (GPC) on a JASCO Gulliver system equipped with two consecutive liner polystyrene gel columns (TOSOH TSKgel $\mathrm{G} 2000 \mathrm{H}_{\mathrm{XL}}$ and $\mathrm{GMH}_{\mathrm{XL}}$ ) at $30^{\circ} \mathrm{C}$, eluted with $\mathrm{CHCl}_{3}$ at a flow rate of $0.085 \mathrm{~mL} / \mathrm{min}$, and calibrated using polystyrene standards. IR spectra were recorded on a JASCO FT/IR-230 spectrometer. Thermogravimetry (TG) was performed on a Shimadzu TGA-50 instrument at a heating rate of $10^{\circ} \mathrm{C} / \mathrm{min}$ under $\mathrm{N}_{2}$ atmosphere (flow rate of $50 \mathrm{~mL} / \mathrm{min}$ ) to determine decomposition temperature $T_{\mathrm{d} 10}$ at which $10 \%$ weight loss was observed. Differential scanning calorimetry (DSC) was carried out using a Shimadzu DSC60 instrument at a heating rate of $10^{\circ} \mathrm{C} / \mathrm{min}$ under $\mathrm{N}_{2}$ atmosphere (flow rate of $50 \mathrm{~mL} / \mathrm{min}$ ) to determine glass transition temperature $T_{\mathrm{g}}$. Melting points were measured with a Stuart Scientific SMP3. MALDITOF-MS spectra were taken on an Shimadzu AXIMA-CFR mass spectrometer. Preparative HPLC was carried out on a JAIFEL LC-418 with JASCO Megapak GEL 201C and JAIFEL 1H gel columns. Wakogel $400 \mathrm{HG}$ was used for column chromatography. Commercial grade adipoyl chloride and 4,4'methylenebis(phenyl isocyanate) (MDI) were distilled under reduced pressure before use. Commercial grade chloroform for spectroscopic analysis was used as solvent. Other chemicals were of reagent grade and used without further purification.

\section{Synthesis}

Bis(formylbenzo)-24-crown-8-ether (1). A trifluoroacetic acid $(20 \mathrm{~mL})$ solution of dibenzo-24-crown8-ether $(5.04 \mathrm{~g}, 10.9 \mathrm{mmol})$ and hexamethylenetetra- mine $(6.11 \mathrm{~g}, 43.6 \mathrm{mmol})$ was heated at $80^{\circ} \mathrm{C}$ for $26 \mathrm{~h}$. After cooling to room temperature, $2.5 \mathrm{~mL}$ of water was added and the resulting mixture was stirred for $12 \mathrm{~h}$. The resulting mixture was extracted three times with $60 \mathrm{~mL}$ of chloroform and the solvent was evaporated. The residue was purified by column chromatography on silica gel (1\% methanol/ chloroform) to give 1 as a colorless solid ( $4.25 \mathrm{~g}, 74.4 \%$ yield).

mp $118-124{ }^{\circ} \mathrm{C} .{ }^{1} \mathrm{H}$ NMR $\left(\mathrm{CDCl}_{3}, 400 \mathrm{MHz}\right) \delta$ $9.82(\mathrm{~d}, 2 \mathrm{H}, J=2.0 \mathrm{~Hz}), 7.43-7.37(\mathrm{~m}, 4 \mathrm{H}, \mathrm{Ar}-\mathrm{H})$, 4.21-4.19 (m, 8H, $\mathrm{H}_{\alpha}$ of DB24C8), 3.97-3.93 (m, 8H, $\mathrm{H}_{\beta}$ of DB24C8), 3.86-3.84 (m, 8H, $\mathrm{H}_{\gamma}$ of DB24C8).

Bis(hydroxymethylbenzo)-24-crown-8 (2). A suspension of $4.25 \mathrm{~g}(8.92 \mathrm{mmol})$ of $\mathbf{1}$ and $1.21 \mathrm{~g}(25.9$ $\mathrm{mmol}$ ) of lithium aluminum hydride in $20 \mathrm{~mL}$ of THF was refluxed for $12 \mathrm{~h}$. The excess lithium aluminum hydride was quenched with sat. sodium sulfate aq. and the resulting mixture was filtered. The filtrate was evaporated and purified by column chromatography on silica gel (2\% methanol/ chloroform) to give $2(2.31 \mathrm{~g}$, 46\%). mp $103-107^{\circ} \mathrm{C} ;{ }^{1} \mathrm{H}$ NMR $\left(\mathrm{CDCl}_{3}, 400 \mathrm{MHz}\right) \delta$ 6.90-6.81 (m, 6H, Ar-H), 4.58 (s, 4H, Ar- $\left.\mathrm{CH}_{2}\right), 4.15-$ $4.13\left(\mathrm{~m}, 8 \mathrm{H}, \mathrm{H}_{\mathrm{a}}\right.$ of DB24C8), 3.92-3.83 $\left(\mathrm{m}, 8 \mathrm{H}, \mathrm{H}_{\mathrm{b}}\right.$ of DB24C8), 3.80-3.70 (m, 8H, $\mathrm{H}_{\gamma}$ of DB24C8).

Poly(crown ether) (3). To a solution of $2(508 \mathrm{mg}$, $1.00 \mathrm{mmol})$ in anhydrous THF $(1.0 \mathrm{~mL})$ was added pyridine $(178 \mu \mathrm{L}, 2.20 \mathrm{mmol})$ and adipoyl chloride $(183 \mathrm{mg}, 1.00 \mathrm{mmol})$ dissolved in anhydrous THF $(1.0 \mathrm{~mL})$. The mixture was heated at $40^{\circ} \mathrm{C}$ for $3 \mathrm{~h}$. The reaction mixture was reprecipitated with methanol. The obtained precipitates were dried in vacuo to give poly(crown ether) (3) (379 mg, 61.2\%). ${ }^{1} \mathrm{H}$ NMR $\left(400 \mathrm{MHz}, \mathrm{CDCl}_{3}\right) \delta$ 6.91-6.81 (m, 6H, Ar-H), 5.00 (s, 4H, 10), 4.58 (s, 10 of termini), 4.14 (t, $J=2.5$ $\mathrm{Hz}, 8 \mathrm{H}, 1), 3.91(\mathrm{t}, J=2.5 \mathrm{~Hz}, 8 \mathrm{H}, 2), 3.86(\mathrm{t}, 2.8$ $\mathrm{Hz}, 8 \mathrm{H}, 3), 2.34(\mathrm{t}, J=2.8 \mathrm{~Hz}, 4 \mathrm{H}, 12), 1.66-1.65(\mathrm{~m}$, $4 \mathrm{H}, 13) ;{ }^{13} \mathrm{C} \mathrm{NMR}\left(\mathrm{CDCl}_{3}, 100 \mathrm{MHz}\right) d 173.1$ (11), 148.8 (5), 148.7 (4), 128.8 (9), 121.7 (8), 113.37 (7), 113.36 (6), 71.3 (3), 69.8 (2), 69.4 (1), 66.2 (10), 33.8 (12), 24.3 (13); IR $(\mathrm{NaCl}) 1730(\mathrm{C}=\mathrm{O}) \mathrm{cm}^{-1}$; $T_{\mathrm{g}} 11.3^{\circ} \mathrm{C}, T_{\mathrm{d} 10} 339^{\circ} \mathrm{C}$. 


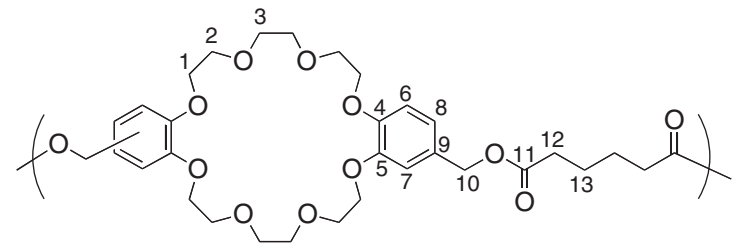

3,5-Di-tert-butyl-N-(6-hydroxyhexyl) benzamide (4). 3,5 -Di-t-buthyl benzoic acid $(41.3 \mathrm{~g}, 176 \mathrm{mmol})$ was dissolved in $94.2 \mathrm{~mol}$ of $\mathrm{SOCl}_{2}$ and the mixture was refluxed for $22 \mathrm{~h}$ under argon atmosphere. The excess $\mathrm{SOCl}_{2}$ was removed thoroughly under reduced pressure. To the residual material was added $500 \mathrm{~mL}$ of anhydrous THF, $25.7 \mathrm{~g}(214 \mathrm{mmol})$ of 6-aminohexanol, and $160 \mathrm{~mL}$ of triethylamine. The resulting mixture was stirred for $2 \mathrm{~d}$ and acidified with $3 \mathrm{M} \mathrm{HCl}$. The mixture was extracted three times with $100 \mathrm{~mL}$ of chloroform and the combined organic layer was washed with $500 \mathrm{~mL}$ of $1 \mathrm{M} \mathrm{HCl}$ and then water. The organic layer was dried over anhydrous magnesium sulfate and then evaporated. The residue was purified by column chromatography on silica gel (2\% methanol/ chloroform) to give $4(52.9 \mathrm{~g}, 90.0 \%)$. $\mathrm{mp} 155-160^{\circ} \mathrm{C}$; ${ }^{1} \mathrm{H} \mathrm{NMR}\left(\mathrm{CDCl}_{3}, 400 \mathrm{MHz}\right) \delta 7.56(\mathrm{~s}, 3 \mathrm{H}, \mathrm{Ar}-\mathrm{H}), 3.66$ $\left(\mathrm{t}, J=3.2 \mathrm{~Hz}, \mathrm{CH}_{2} \mathrm{OH}\right), 3.48(\mathrm{t}, J=5.1 \mathrm{~Hz}, \mathrm{CON}-$ $\left.\mathrm{HCH}_{2}\right), 1.65-1.47\left(\mathrm{~m}, 8 \mathrm{H}, \mathrm{CH}_{2}\right) 1.35\left(\mathrm{~s}, 18 \mathrm{H},{ }^{\mathrm{t}} \mathrm{Bu}\right)$.

$N$-(3,5-Di-tert-butylbenzyl)- $N$-(6-hydroxyhexyl)ammonium Hexafluorophosphate (5). A suspension of $4.76 \mathrm{~g}(14.3 \mathrm{mmol})$ of $4,2.71 \mathrm{~g}(71.5 \mathrm{mmol})$ of lithium aluminum hydride and $50 \mathrm{~mL}$ of THF was stirred for $8 \mathrm{~h}$ in an ice bath. To the mixture was added sat. $\mathrm{Na}_{2} \mathrm{SO}_{4}$ aq. to quench excess lithium aluminum hydride. The mixture was filtered and the residue was washed with ethyl acetate. The combined filtrate was evaporated to give the colorless oil including $\mathrm{N}$-(3,5-di-tert-butylbenzyl)- $N$-(6-hydroxyhexyl)amine. The crude product was dissolved in $20 \mathrm{~mL}$ of methanol and $5 \% \mathrm{HPF}_{6}$ aq. was added until no white precipitate was deposited. Water $(100 \mathrm{~mL})$ was added to the mixture to precipitate the product. The precipitate was collected by filtration and $5 \% \mathrm{HPF}_{6}$ aq. was added to the filtrate. This procedure was repeated three times to give $5(5.53 \mathrm{~g}, 82.4 \%) .{ }^{1} \mathrm{H}$ NMR $\left(400 \mathrm{MHz}, \mathrm{CDCl}_{3}\right) \delta$ 7.52 (s, 3), 7.28 (s, 2H, 5), 4.19 (s, 2H, 6), 3.53 (t, $J=$ $3.2 \mathrm{~Hz}, 12), 2.99(\mathrm{t}, J=3.6 \mathrm{~Hz}, 2 \mathrm{H}, 7), 1.91(\mathrm{br}, 1 \mathrm{H}$, $\mathrm{OH}), 1.78-1.69(\mathrm{~m}, 2 \mathrm{H}, 8), 1.49-1.42(\mathrm{~m}, 2 \mathrm{H}, 11)$, $1.36-1.33(\mathrm{~m}, 4 \mathrm{H}, 9$ and 10$), 1.32(\mathrm{~s}, 18 \mathrm{H}, 1)$; ${ }^{13} \mathrm{C}$ NMR $\left(100 \mathrm{MHz}, \mathrm{CDCl}_{3}\right) \delta 152.1$ (2), 129.1 (4), 124.2 (5), 123.6 (3), 62.1 (12), 52.2 (6), 46.6 (7), 34.9 (8), 31.5 (11), 31.3 (1), 25.5 (9), 24.7 (10); IR (NaCl) $1603\left(\mathrm{~N}^{+}-\mathrm{H}_{2}\right), 845(\mathrm{P}-\mathrm{F}), 557(\mathrm{P}-\mathrm{F}) \mathrm{cm}^{-1}$.

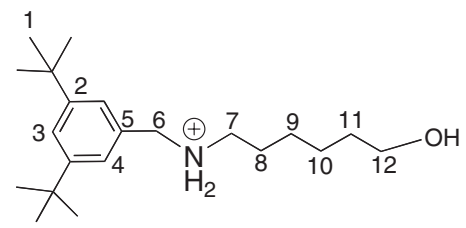

Model [2] rotaxane (6). A mixture of DB24C8 (100 mg, $223 \mu \mathrm{mol})$ and $5(100 \mathrm{mg}, 213 \mu \mathrm{mol})$ was dissolved in $\mathrm{CHCl}_{3}(0.500 \mathrm{~mL})$ and the mixture was stirred for $9 \mathrm{~h}$. 3,5-Dimetylphenylisocyanate $38.2 \mu \mathrm{l}$ $(255 \mu \mathrm{mol})$ and di $(n$-butyl)tin dilaurate $(15.3 \mu \mathrm{l}, 25.5$ $\mu \mathrm{mol})$ were added to the mixture. The resulting mixture was stirred for $12 \mathrm{~h}$ and concentrated under reduced pressure. The reaction mixture was purified with a preparative HPLC (eluent: chloroform). The substance having higher molecular weight was collected and dried in vacuo to give 6 (123 mg, 54.5\%). ${ }^{1} \mathrm{H}$ NMR $\left(\mathrm{CDCl}_{3}, 400 \mathrm{MHz}\right) \delta 7.53(\mathrm{~s}, 1 \mathrm{H}, 3), 7.38$ (s, 2H, 13), 7.09 (s, 2H, 5), 6.67 (s, 1H, 14), 4.654.62, (m, 6), 4.27-4.23 (m, 4H, $\alpha), 4.11-4.08(\mathrm{~m}, 4 \mathrm{H}$, $\alpha), 3.96(\mathrm{t}, J=6.22 \mathrm{H}, 12), 3.82-3.74(\mathrm{~m}, 8 \mathrm{H}, \beta)$, $3.72-3.59(\mathrm{~m}, 4 \mathrm{H}, \gamma), 3.38-3.34(\mathrm{~m}, 4 \mathrm{H}, \gamma), 3.12(\mathrm{t}$, $J=6.6 \mathrm{~Hz}, 2 \mathrm{H}, 7), 2.33(\mathrm{~s}, 6 \mathrm{H}, 15), 1.36-1.34(\mathrm{~m}$, $4 \mathrm{H}, 8$ and 11$), 1.25-1.23(\mathrm{~m}, 18 \mathrm{H}, 1), 1.05-0.97(\mathrm{~m}$, 4H, 9 and 10).

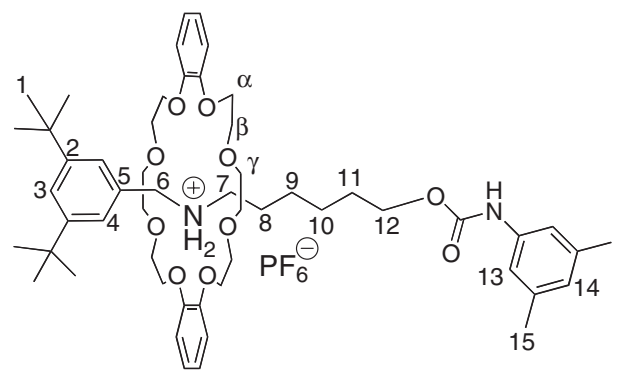

Polypseudorotaxane (7). A typical procedure (Table I, run 11): $\mathrm{A} \mathrm{CDCl}_{3}$ solution of an equimolar $(60.5 \mathrm{mM})$ mixture of poly(crown ether) $(3)$ and the axle (5) was allowed to stand for $3 \mathrm{~d}$ at $25^{\circ} \mathrm{C}$ to afford polypseudorotaxane (7). The ${ }^{1} \mathrm{H}$ NMR spectrum of the sample was measured to evaluate the yield (Figure 3).

Polyrotaxane (8). A solution of a mixture of $3(100 \mathrm{mg}, 162 \mu \mathrm{mol})$ and $5(152 \mathrm{mg}, 323 \mu \mathrm{mol})$ in $\mathrm{CDCl}_{3}(2.00 \mathrm{~mL})$ was stirred for $12 \mathrm{~h}$ at $25^{\circ} \mathrm{C}$. To the solution were added 3,5-dimethylphenylisocyanate $(57.0 \mathrm{mg}, 388 \mu \mathrm{mol})$ and di $(n$-butyl)tin dilaurate $(24.5 \mu \mathrm{L}, 38.8 \mu \mathrm{mol})$. After stirring at $25^{\circ} \mathrm{C}$ for $12 \mathrm{~h}$, $10 \mathrm{~mL}$ of methanol was added to precipitate polymeric material. The precipitate was collected by filtration and dried in vacuo to give 8 (102 mg, 47.8\%). ${ }^{1} \mathrm{H}$ NMR $\left(\mathrm{CDCl}_{3}, 400 \mathrm{MHz}\right) \delta 7.38-7.29(\mathrm{~m}, 1 \mathrm{H}, 15), 7.29(\mathrm{~s}$, $2 \mathrm{H}, 24), 7.17-6.89(\mathrm{~m}, 8 \mathrm{H}, 13,1$ and 2$), 6.65(\mathrm{~s}, 1 \mathrm{H}$, 26), 5.09-4.97 (m, 4H, 7), 4.62-4.59 (m, 2H, 16), 4.344.24 (br, 4H, 4), 4.21-4.00 (br, 4H, 4), 4.09-3.88 (m, $2 \mathrm{H}, 21$ ), 3.79-3.73 (br, 8H, 5), 3.65-3.60 (br, 4H, 6), 3.44-3.36 (br, 4H, 6), 2.30 (s, 4H, 9), 2.26-2.22 (m, $6 \mathrm{H}, 27), 1.66(\mathrm{~s}, 4 \mathrm{H}, 10), 1.41-1.31(\mathrm{~m}, 4 \mathrm{H}, 18$ and 20), $1.22(\mathrm{~s}, 18 \mathrm{H}, 11), 1.11-1.02(\mathrm{~m}, 4 \mathrm{H}, 19)$; ${ }^{13} \mathrm{C}$ NMR $\left(\mathrm{CDCl}_{3}, 100 \mathrm{MHz}\right) 173.3$ (8), 151.3 (12), 148.8 (22), 147.4 (3), 138.5 (23, 25), $131.6(26), 129.5$ (14), 124.2 (13), 123.2 (15), 121.9 (1), 116.2 (24), 


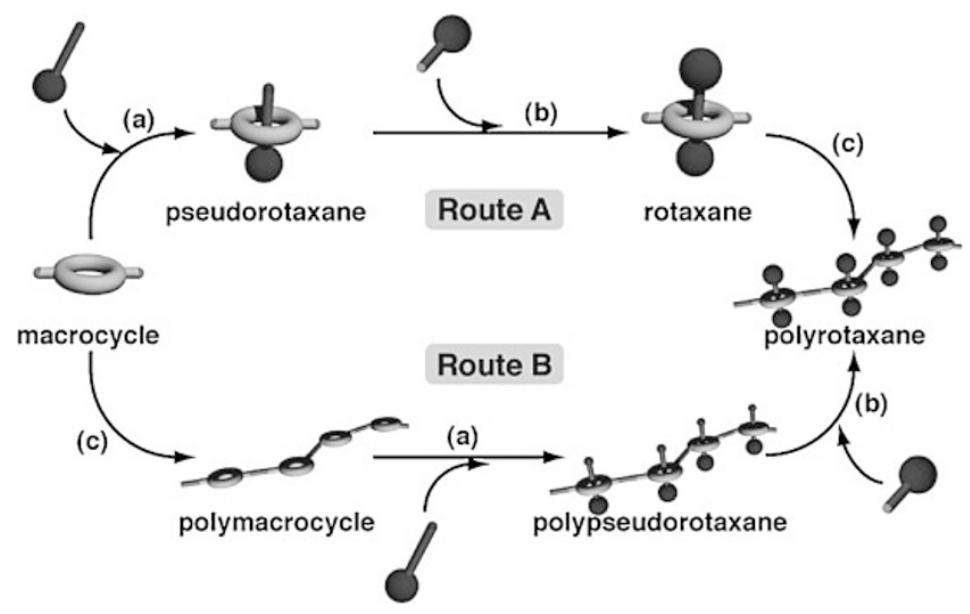

Figure 2. Synthetic strategy of a main chain-type polyrotaxane. (a) pseudorotaxanation, (b) end-capping (c) polymerization.

112.9 (24), 112.5 (2), 70.5 (6), 69.9 (5), 69.4 (4), 68.3 (7), 65.8 (21), 52.7 (16), 49.0 (17), 34.8 (18), 33.8 (9), 31.7 (20), 31.3 (11), 28.4 (19), 24.9 (10), 24.2 (19), 21.4 (27). IR: $3396(\mathrm{~N}-\mathrm{H}), 1730(\mathrm{C}=\mathrm{O}), 844(\mathrm{P}-\mathrm{F})$, $558(\mathrm{P}-\mathrm{F}) \mathrm{cm}^{-1}$.

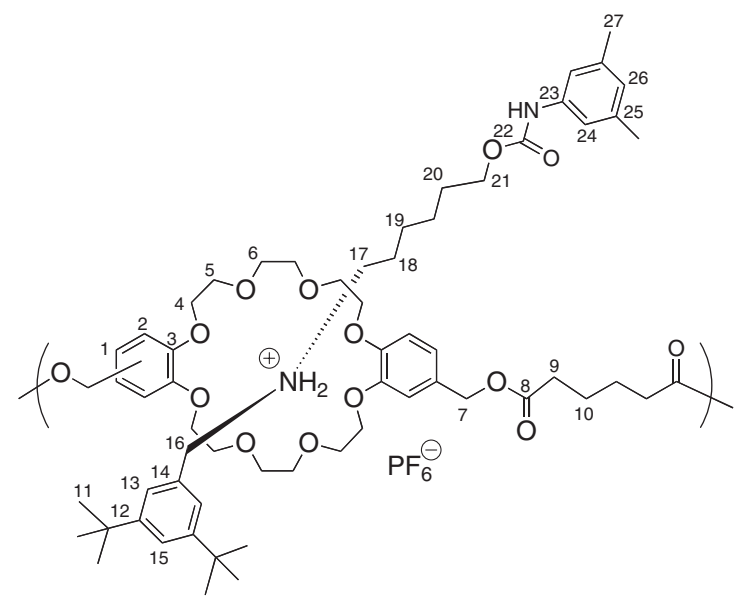

$N$-Acetylated polyrotaxane (9). To a solution of $\mathbf{8}$ $(124 \mathrm{mg}, 0.100 \mathrm{mmol})$ in DMF $(1.5 \mathrm{~mL})$ were added triethylamine $(69.5 \mu \mathrm{L}, 0.500 \mathrm{mmol})$ and acetic anhydride $(33.0 \mu \mathrm{L}, 0.300 \mathrm{mmol})$. The mixture was stirred for $2 \mathrm{~d}$ at $25^{\circ} \mathrm{C}$. After addition of $3 \mathrm{M} \mathrm{HCl}(20 \mathrm{~mL})$, the resulting mixture was extracted three times with chloroform. The combined chloroform layer was dried over anhydrous $\mathrm{MgSO}_{4}$ and filtered. The concentrated filtrate was purified by a preparative HPLC to yield 9 $(53 \mathrm{mg}, 55 \%) .{ }^{1} \mathrm{H} \mathrm{NMR}\left(\mathrm{CDCl}_{3}, 400 \mathrm{MHz}\right) \delta 7.11-$ $6.48(\mathrm{~m}, 12 \mathrm{H}, \mathrm{Ar}-\mathrm{H}), 5.00$ (s, 4H, Ar- $\left.\mathrm{CH}_{2}\right), 4.15-4.09$ (br, $8 \mathrm{H}, \mathrm{H}_{\alpha}$ of DB24C8), $3.90-3.82\left(\mathrm{br}, 8 \mathrm{H}, \mathrm{H}_{\beta}\right.$ of DB24C8), 3.54-3.52 (br, 8H, $\mathrm{H}_{\gamma}$ of DB24C8), 2.34 (m, 4H, $\mathrm{OCOCH}_{2}$ ), 2.28-2.27 (m, 4H, acetyl), 2.08 (m, 6H, Me), 1.30-1.21 (m, 28H, ${ }^{t} \mathrm{Bu}$ and $\left.\mathrm{CH}_{2}\right), 0.89$ 087 (m, 4H, $\mathrm{CH}_{2}$ ); IR 1635 (C=O amide), 844 (P-F), $558(\mathrm{P}-\mathrm{F}) \mathrm{cm}^{-1}$.

Polyrotaxane network (10). A chloroform (0.250 $\mathrm{mL})$ solution of $100 \mathrm{mg}(162 \mu \mathrm{mol})$ of $\mathbf{3}$ and $76.0 \mathrm{mg}$
$(162 \mu \mathrm{mol})$ of 5 was stirred for $3 \mathrm{~d}$ at $25^{\circ} \mathrm{C}$ and then $24.3 \mathrm{mg}(81.0 \mu \mathrm{mol})$ of MDI and $9.8 \mu \mathrm{l}(16.2 \mu \mathrm{mol})$ of di( $n$-butyl)tin dilaurate were added to the mixture. Within $4 \mathrm{~h}$, the initial homogeneous solution was changed to gelled material. The mixture was allowed to stand for $12 \mathrm{~h}$. The gelled product was washed with chloroform and methanol and the washing was repeated three times. The product was dried in vacuo to give 10 (191 mg, 96\%).

\section{RESULTS AND DISCUSSION}

\section{Synthetic Strategy}

Two typical approaches to the main chain-type polyrotaxane (B) are illustrated in Figure 2. While one is to polymerize functionalized rotaxane monomer (Route A), the other is to undergo rotaxanation of polymer containing wheel units (Route B). Each approach has both advantageous and disadvantageous aspects. Route A involves an effective procedure of successive connection of monomer with definite rotaxane structure to give completely rotaxanated main chain. However, Route A often suffers from synthetic difficulty because rotaxanated monomer should be highly functionalized, i.e. the monomer is prepared via initial pseudorotaxanation between functionalized wheel and axle components followed by end-capping. This limits not only the monomer synthesis but also its polymerization. On the other hand, in Route B, final step to polyrotaxane meets often difficulty due to the polymer reaction often with low efficiency. However, the procedures of Route B are usually simple and easy to achieve. So, we decided to synthesize the main chain-type polyrotaxane (B) through Route B.

To accomplish the synthesis through Route B, a combination of crown ether wheel and sec-ammonium salt axle was chosen as motifs of the rotaxane skeleton, because of the tolerance to versatile skeletal mod- 

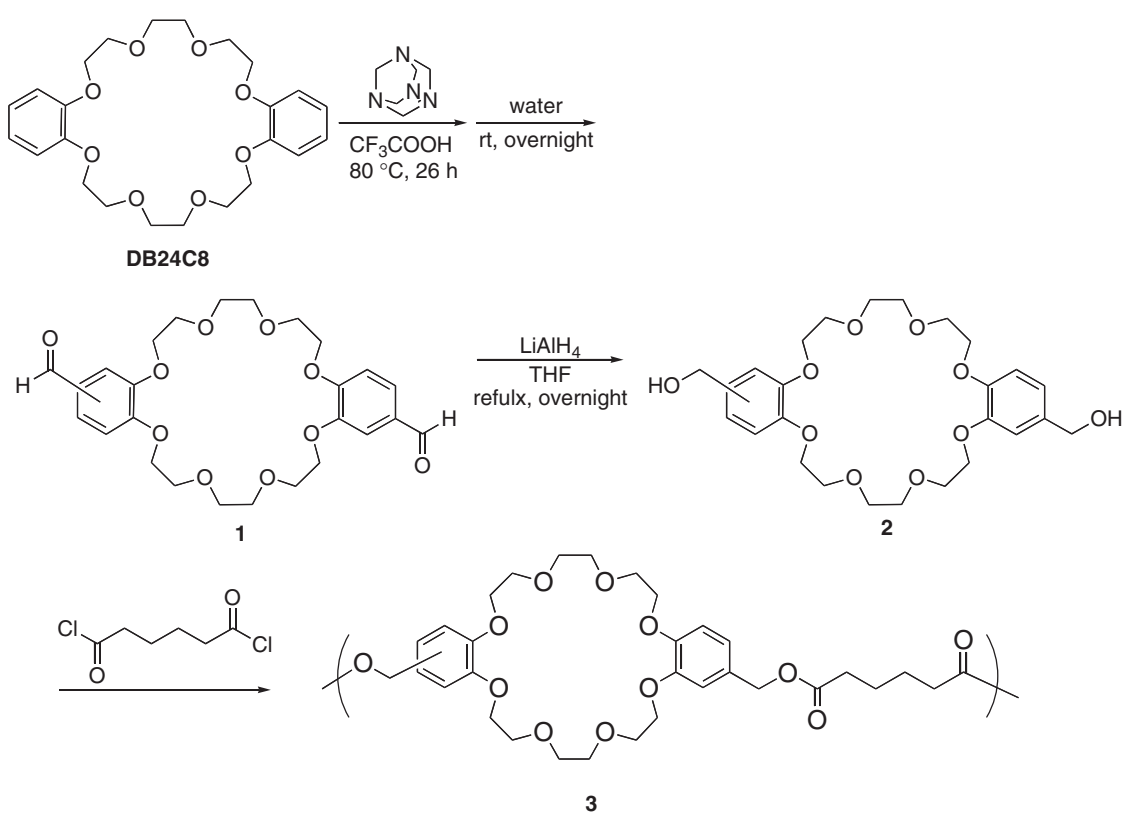

Scheme 1.
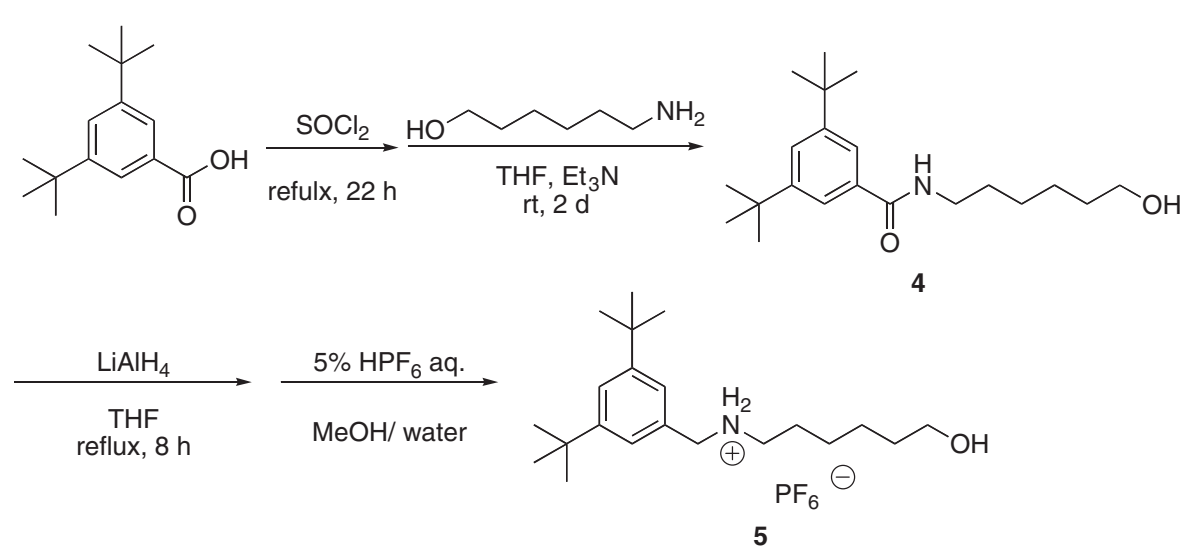

Scheme 2.

ifications. The rotaxane skeleton was constructed according to the threading-end-capping protocol by urethane end-capping with a bulky isocyanate, because of its simplicity and high efficiency. ${ }^{18}$

\section{Synthesis of Wheel and Axle Components}

Poly(crown ether) 3, a polymer having many macrocyclic units in the main chain, was prepared in $61 \%$ yield $\left(M_{\mathrm{w}} 4000, M_{\mathrm{w}} / M_{\mathrm{n}} 1.68\right.$ by GPC) by the polycondensation of adipoyl chloride and bis(hydroxymethylbenzo)-24-crown-8-ehter 1 (Scheme 1). Since the double hydroxymethylation on the aromatic rings of DB24C8 was not regioselectively carried out, $\mathbf{1}$ consisted of two regioisomer with syn and anti forms, and therefore $\mathbf{3}$ was not a single isomer. Poly(crown ether) 3 obtained here was well-soluble in ordinary organic solvents such as chloroform, THF, DMSO, but insoluble in methanol, acetonitrile, and water. Axle component 5 was synthesized starting from 3,5-di-t- butylbenzoic acid according to our previous report (Scheme 2). ${ }^{19}$

\section{Pseudorotaxanation}

In the rotaxane synthesis by the end-capping method, ${ }^{20}$ the most important thing is how to enhance the efficiency of pseudorotaxane formation before endcapping. This is the case in the synthesis of main chain-type polyrotaxane (B) and therefore to clarify the details such as degree, rate, and efficiency of the formation of polypseudorotaxane (Figure 2) is of quite significance for not only enhanced yield of the polyrotaxane but also controlled incorporation ratio of the rotaxanated units. Prior to the end-capping of polypseudorotaxane to polyrotaxane, pseudorotaxanation between poly(crown ether) $\mathbf{3}$ and sec-ammonium salt 5 as a half axle component was evaluated under various conditions by means of ${ }^{1} \mathrm{H}$ NMR spectroscopy.

For the structure determination and evaluation of 


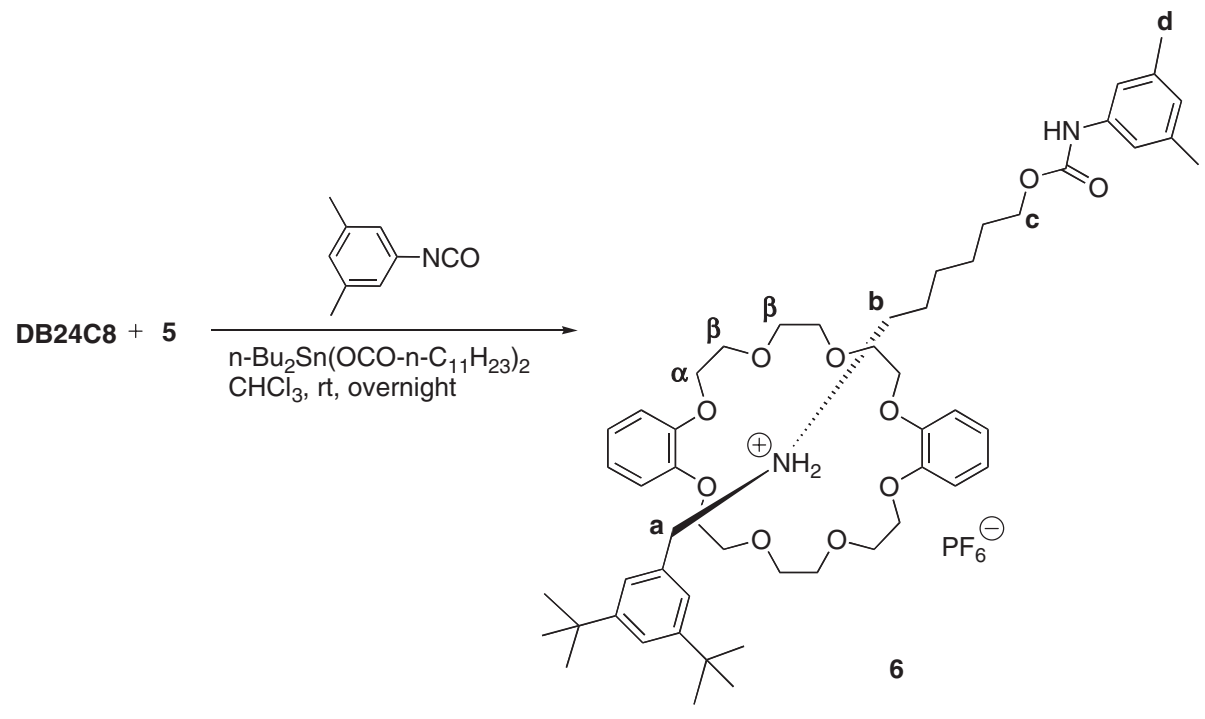

Scheme 3.
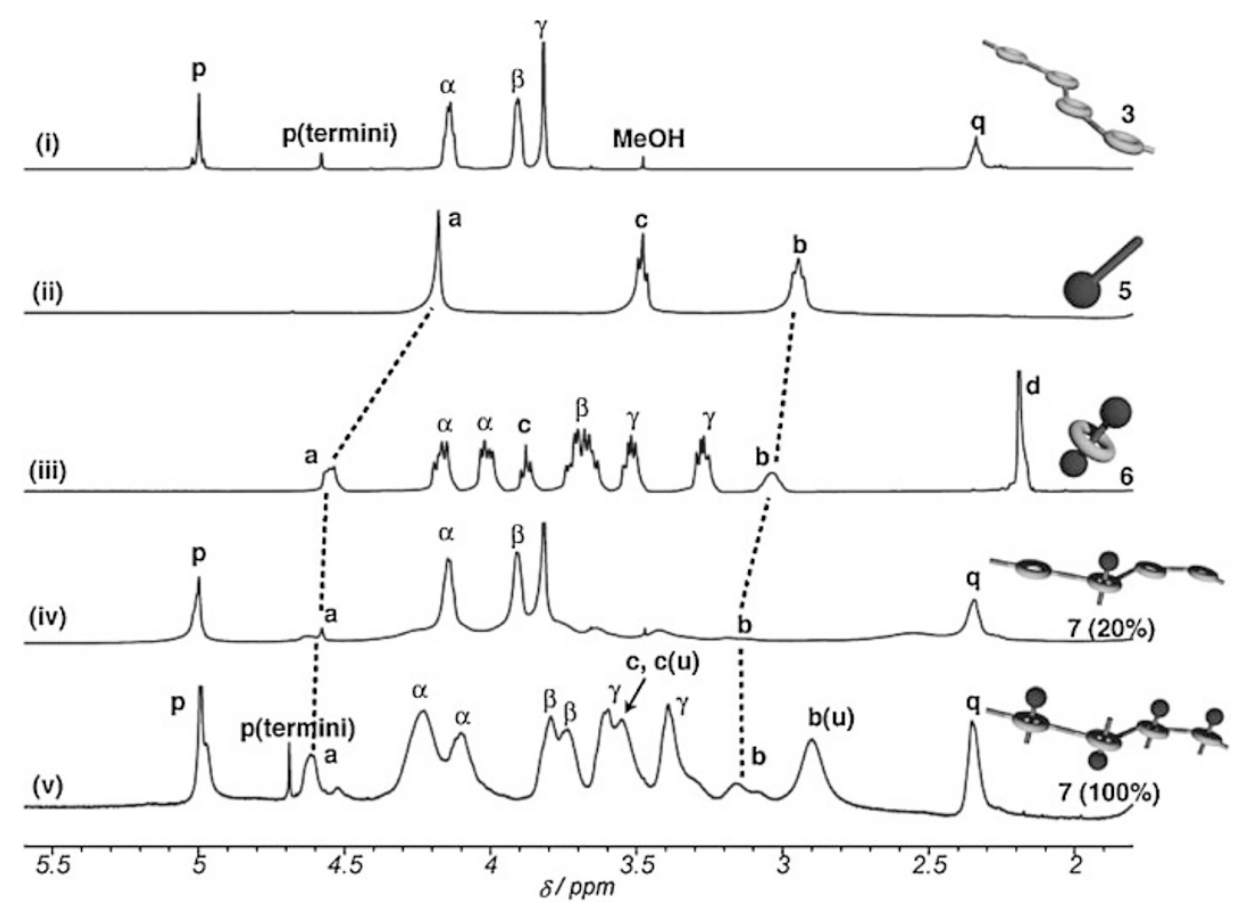

Figure 3. Partial ${ }^{1} \mathrm{H}$ NMR spectra of (i) wheel 3, (ii) axle 5, (iii) model [2]rotaxane 6, (iv) polypseudorotaxane 7 with $20 \%$ rotaxanation ratio, and (v) fully complexed polypseudorotaxane $7\left(400 \mathrm{MHz}, \mathrm{CDCl}_{3}, 25^{\circ} \mathrm{C}\right)$. Sample for the spectrum (v) includes unreacted axle 5 (signals $\mathrm{b}(\mathrm{u})$ and $\mathrm{c}(\mathrm{u})$ ). For symbols of the signals, see Schemes 3 and 4.

the pseudorotaxanation, a model compound, [2]rotaxane 6, was prepared by the initial complexation between 5 and DB24C8 followed by the end-capping with 3,5-dimethylphenyl isocyanate catalyzed by di(n-butyl)tin dilaurate ${ }^{18}$ (Scheme 3). Partial ${ }^{1} \mathrm{H}$ NMR spectra of axle 5 (ii) and 6 (iii) are shown in Figure $3 .{ }^{21}$ The downfield shift of the benzyl proton signal a from 4.18 (ii) to $4.60 \mathrm{ppm}$ (iii) in the axle unit evidently revealed the rotaxane formation. ${ }^{22}$ This big shift strongly suggested that the present NMR change can be applied to evaluate the degree of the pseudo- rotaxanation (Scheme 4). Then, yield of polypseudorotaxane 7 was determined from the integral ratio of signals $\mathbf{a}$ and $\mathbf{q}$ of the ${ }^{1} \mathrm{H}$ NMR spectrum of an equimolar mixture of $\mathbf{3}$ and $\mathbf{5}$ in a deuterated solvent (Figure 3). The results are summarized in Table I.

Since the rotaxane formation related closely to the pseudorotaxane formation is solvent-dependent, especially solvent donor number $(D N)$-dependent, ${ }^{4 e, 22 b}$ the choice of solvent largely affects the ratio of pseudorotaxanation. Table I (run 1-3) shows the effect of solvent on the pseudorotaxanated ratio determined by 


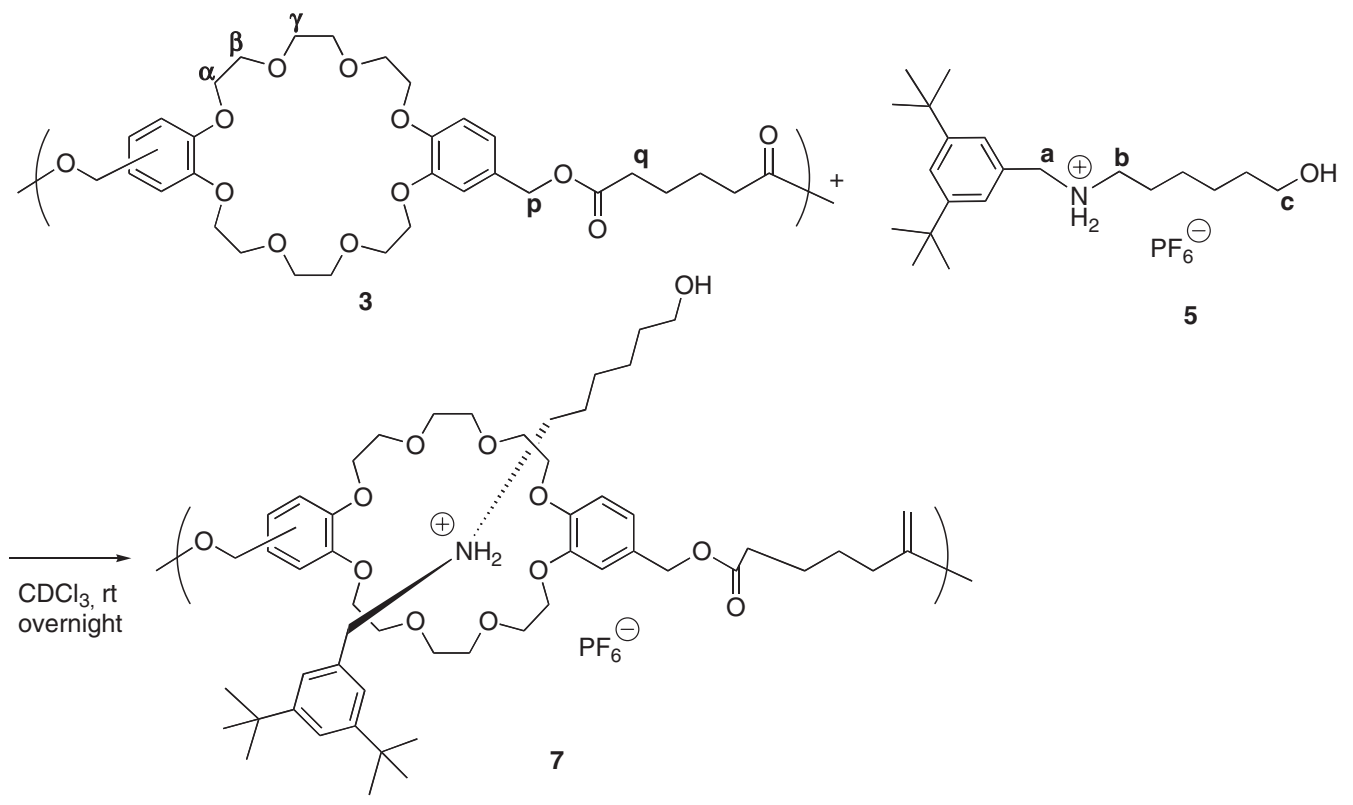

Scheme 4.

Table I. Effects of solvent, temperature, time and concentration on the pseudorotaxanation (Scheme 4) ${ }^{\mathrm{a})}$

\begin{tabular}{ccccccc}
\hline run & solvent & donor number & temp $/{ }^{\circ} \mathrm{C}$ & time $/ \mathrm{h}$ & concentration of $\mathbf{3}$ and $\mathbf{5} / \mathrm{mM}$ & rotaxanated ratio/\% \\
\hline 1 & $\mathrm{CDCl}_{3}$ & 4.0 & 25 & 9 & 60.5 & 79 \\
2 & $\mathrm{CD}_{3} \mathrm{NO}_{2}$ & 2.7 & 25 & 9 & 60.5 & 84 \\
3 & $\mathrm{DMSO}_{4}$ & 29.8 & 25 & 9 & 60.5 & 0 \\
4 & $\mathrm{CDCl}_{3}$ & & 0 & 9 & 60.5 & 93 \\
5 & $\mathrm{CDCl}_{3}$ & & -25 & 9 & 60.5 & 90 \\
6 & $\mathrm{CDCl}_{3}$ & & 25 & 10 min & 60.5 & 55 \\
7 & $\mathrm{CDCl}_{3}$ & & 25 & 1 & 60.5 & 62 \\
8 & $\mathrm{CDCl}_{3}$ & 25 & 5 & 60.5 & 79 \\
9 & $\mathrm{CDCl}_{3}$ & & 25 & $1 \mathrm{~d}$ & 60.5 & 78 \\
10 & $\mathrm{CDCl}_{3}$ & & 25 & $3 \mathrm{~d}$ & 60.5 & 82 \\
$11^{\mathrm{b})}$ & $\mathrm{CDCl}_{3}$ & & 25 & $3 \mathrm{~d}$ & 60.5 & 78 \\
12 & $\mathrm{CDCl}_{3}$ & & 25 & 9 & 72.5 & 80 \\
13 & $\mathrm{CDCl}_{3}$ & 25 & 9 & 120 & 75 \\
\hline
\end{tabular}

a) Poly(crown ether) $\left(3, M_{\mathrm{w}} 4000, M_{\mathrm{w}} / M_{\mathrm{n}} 1.68\right)$ was used. b) Poly(crown ether) $\left(3, M_{\mathrm{w}} 10000, M_{\mathrm{w}} / M_{\mathrm{n}} 2.39\right)$ was used.

${ }^{1} \mathrm{H}$ NMR spectra. In chloroform ( $D N$ 4.0) and nitromethane (DN 2.7), the pseudorotaxanated ratio was sufficiently high, $79 \%$ and $84 \%$, respectively. However, no pseudorotaxane was observed in DMSO (DN 29.8), being consistent with that solvents having higher DNs such as DMSO disturb the hydrogen bonding between the wheel and axle components to reduce the pseudorotaxanation ratio. ${ }^{22 \mathrm{~b}}$ Due to the equilibrium character of the pseudorotaxanation, the rotaxanated ratio went up to $93 \%$ at $0{ }^{\circ} \mathrm{C}$ (run 4) which was compared with that at $25^{\circ} \mathrm{C}$ (run 1, 79\%). Slight decrease of the pseudorotaxanation ratio at $-25^{\circ} \mathrm{C}$ (run 5) can be attributed to the low solubility of $\mathbf{5}$ under the condition.

Effect of reaction time (run 1, 6-10) seems to indicate that the equilibrium rate of the pseudorotaxanation is not fast. It takes about $5 \mathrm{~h}$ to reach the equilib- rium state where the rotaxanation ratio is $c a .80 \%$ under the conditions employed. Effect of molecular weigh of $\mathbf{3}$ on the pseudorotaxanation was concluded to be small, because the pseudorotaxanated ratio was little changed when 3 with $M_{\mathrm{w}} 10000$ was used (runs 10 and 11). Meanwhile, elevated concentration of $\mathbf{3}$ and 5 (runs 12 and 13) did not cause the increase in pseudorotaxanation ratio. This result can be accounted for by the polarity increase by the concentration increase which reduces the complexation between $\mathbf{3}$ and $\mathbf{5}$ as reported previously. ${ }^{22 \mathrm{c}}$

We examined some additional experiments for the arbitrary control of rotaxanated ratio in the polyrotaxane (Table II). When the 0.2 equiv. of 5 to $\mathbf{3}$ was added, $c a .20 \%$ of the rotaxanated ratio was obtained (run 1 and Figure 3 (iv)). Small benzylic proton signal a appeared at $4.6 \mathrm{ppm}$ in the ${ }^{1} \mathrm{H}$ NMR spectrum. The 
rotaxanated ratio increased proportionally with an increase in feed ratio of 5 (run 1-6). It is notable that the complete pseudorotaxanation (>99\%) was achieved when 2 equiv. of 5 to $\mathbf{3}$ was added (run 6). As shown in Figure $3(\mathrm{v})$, all oxyethylene protons of the wheel component were split like the case of the model [2]rotaxane (iii), indicating the occurrence of the complete pseudorotaxanation. These results revealed that the rotaxanated ratio could be finely tuned by changing the

Table II. Effect of feed ratio of $\mathbf{3}$ and

5 on the pseudorotaxanation ${ }^{\mathrm{a}}$

\begin{tabular}{clc}
\hline Run & $\mathbf{3 : 5}^{\text {b }}$ & rotaxanated ratio/\% \\
\hline 1 & $1: 0.2$ & 20 \\
2 & $1: 0.8$ & 62 \\
3 & $1: 1$ & 79 \\
4 & $1: 1.2$ & 82 \\
5 & $1: 1.5$ & 92 \\
6 & $1: 2$ & $>99$ \\
\hline
\end{tabular}

a) Reaction condition; $\mathrm{CDCl}_{3}, 25^{\circ} \mathrm{C}$, and [1] $60.5 \mathrm{mM}$.

b) The molar ratio of $\mathbf{3}$ to $\mathbf{5}$. feed ratio of 5 to 3 . The complex formation constant $K_{3.5}$ was $16.2 \mathrm{~L} \mathrm{~mol}^{-1}$ as determined by the ${ }^{1} \mathrm{H} \mathrm{NMR}$ analysis.

\section{End-capping to Polyrotaxane and Its Characteriza- tion}

The end-capping of polypseudorotaxane 7 to polyrotaxane 8 was carried out via the urethane end-capping protocol. ${ }^{18}$ The end-capping of 7 prepared in situ (pseudorotaxanated ratio: 82\%) with 3,5-dimethylphenyl isocyanate catalyzed by di(n-butyl)tin dilaurate in anhydrous chloroform gave polyrotaxane 8 in $84 \%$ yield (Scheme 5). Two indicative ${ }^{1} \mathrm{H}$ NMR signals of methylene protons a at $4.6 \mathrm{ppm}$ and $\mathbf{q}$ at $2.4 \mathrm{ppm}$ clearly supported the polyrotaxane structure of 7 along with the methyl proton signal of the endcap appeared around $2.3 \mathrm{ppm}$ (Figure 4 (A)). Further, the spectral pattern of $\mathbf{8}$ at $2-5 \mathrm{ppm}$ was very similar to that of polypseudorotaxane 7 in Figure 3 (v). From the ${ }^{1} \mathrm{H}$ NMR integration study, the rotaxanated ratio in 8 was determined as $83 \% .{ }^{13} \mathrm{C}$ NMR spectrum of $\mathbf{7}$ was measured and compared with those of $\mathbf{3}$ and $\mathbf{5}$

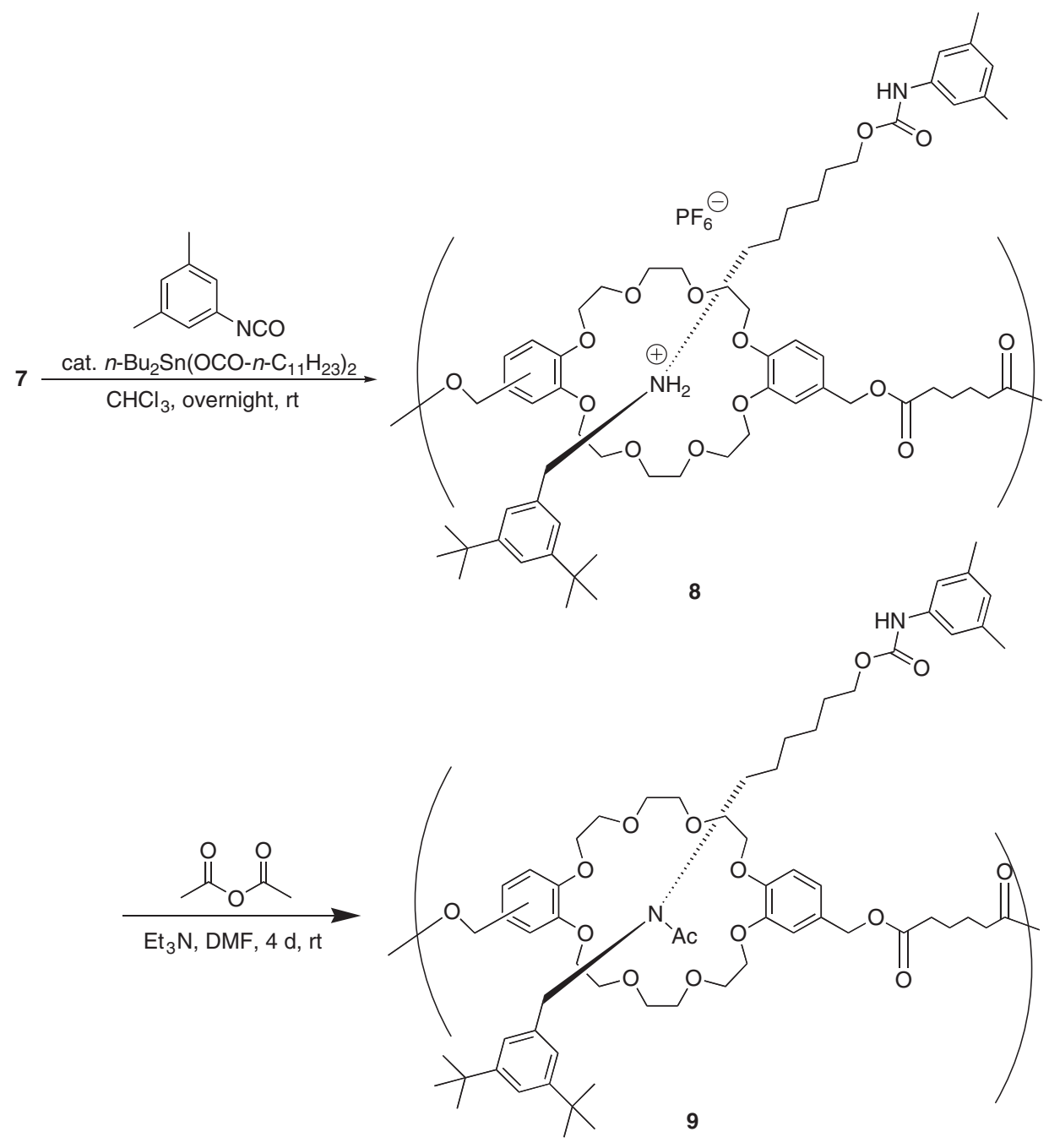

Scheme 5. 
(A)

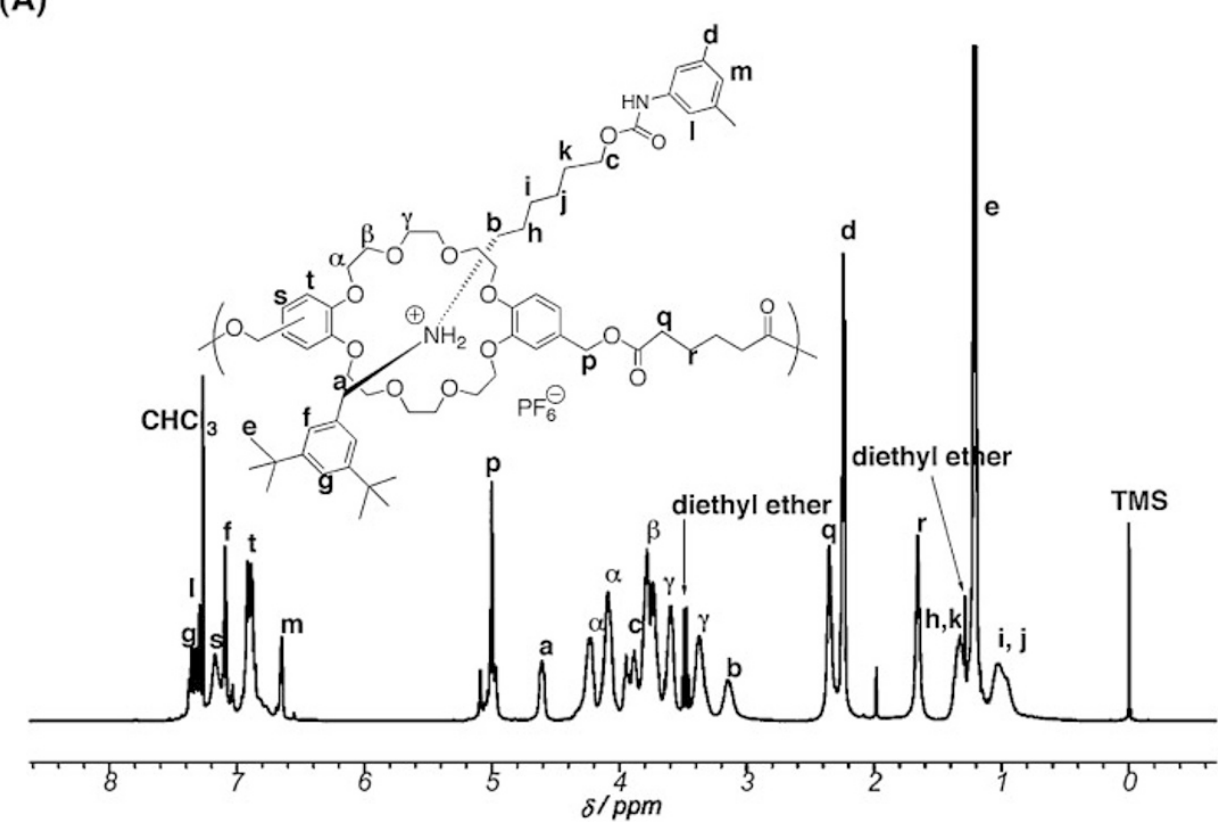

(B)

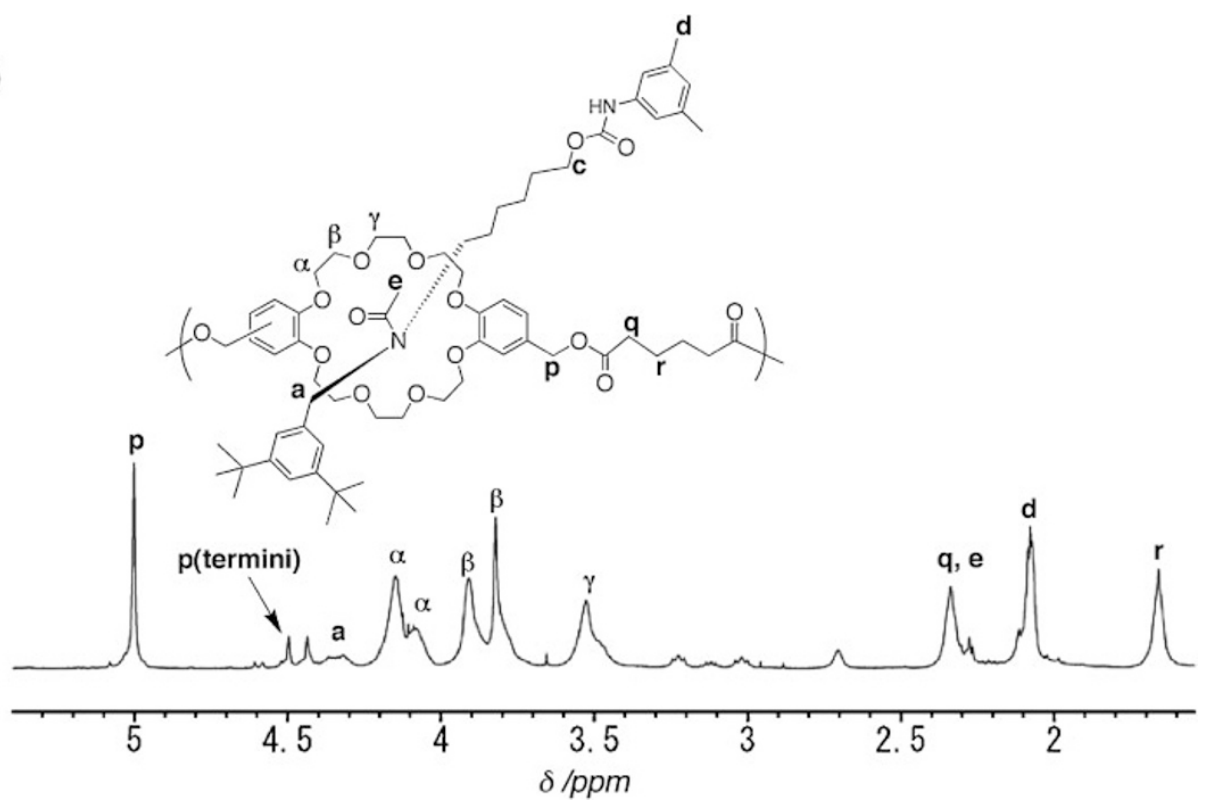

Figure 4. ${ }^{1} \mathrm{H}$ NMR spectra of (A) polyrotaxane 8 and (B) $N$-acetylated polyrotaxane $9\left(400 \mathrm{MHz}, 298 \mathrm{~K}, \mathrm{CDCl}_{3}\right)$. Several signals were assigned for 9 .

(Figure 5). The spectrum was almost superimposed by those of the components except for the signals of the end-cap group. Meanwhile, in the IR spectrum of 7, both absorptions of $\mathrm{C}=\mathrm{O}$ of the urethane moiety $\left(1730 \mathrm{~cm}^{-1}\right)$ and P-F of the counter anion (843, $558 \mathrm{~cm}^{-1}$ ) were confirmed. These spectral data coincided with the proposed structure of $\mathbf{8}$.

Furthermore, from completely complexed polypseudorotaxane 7 (Table II, run 6), polyrotaxane 8 having a rotaxanated ratio more than $99 \%$ was obtained in $84 \%$ yield. Thus, the present end-capping strategy can be regarded as an effective entry to preparation of the main chain-type polyrotaxane (B) with controlled rotaxanated ratio.
Because polyrotaxane $\mathbf{8}$ was a polymeric ion complex, its solubility in organic solvents was low enough to prevent the molecular weight determination by GPC. Furthermore, the strong hydrogen bonding between the ammonium salt axle and the crown ether wheel limits the mobility of the components, which is the most important characteristic of polyrotaxane. Thus, the cationic sites on the axle of $\mathbf{8}$ were neutralized. The ammonium nitrogen was acetylated with acetic anhydride in the presence of triethylamine ${ }^{22 c}$ to give neutral polyrotaxane 9 in 55\% yield (Scheme 5) after purification by the preparative HPLC. The IR peaks at 843 and $558 \mathrm{~cm}^{-1}$ identified as $\mathrm{PF}_{6}{ }^{-}$salt clearly disappeared after the $\mathrm{N}$-acetylation, while the 

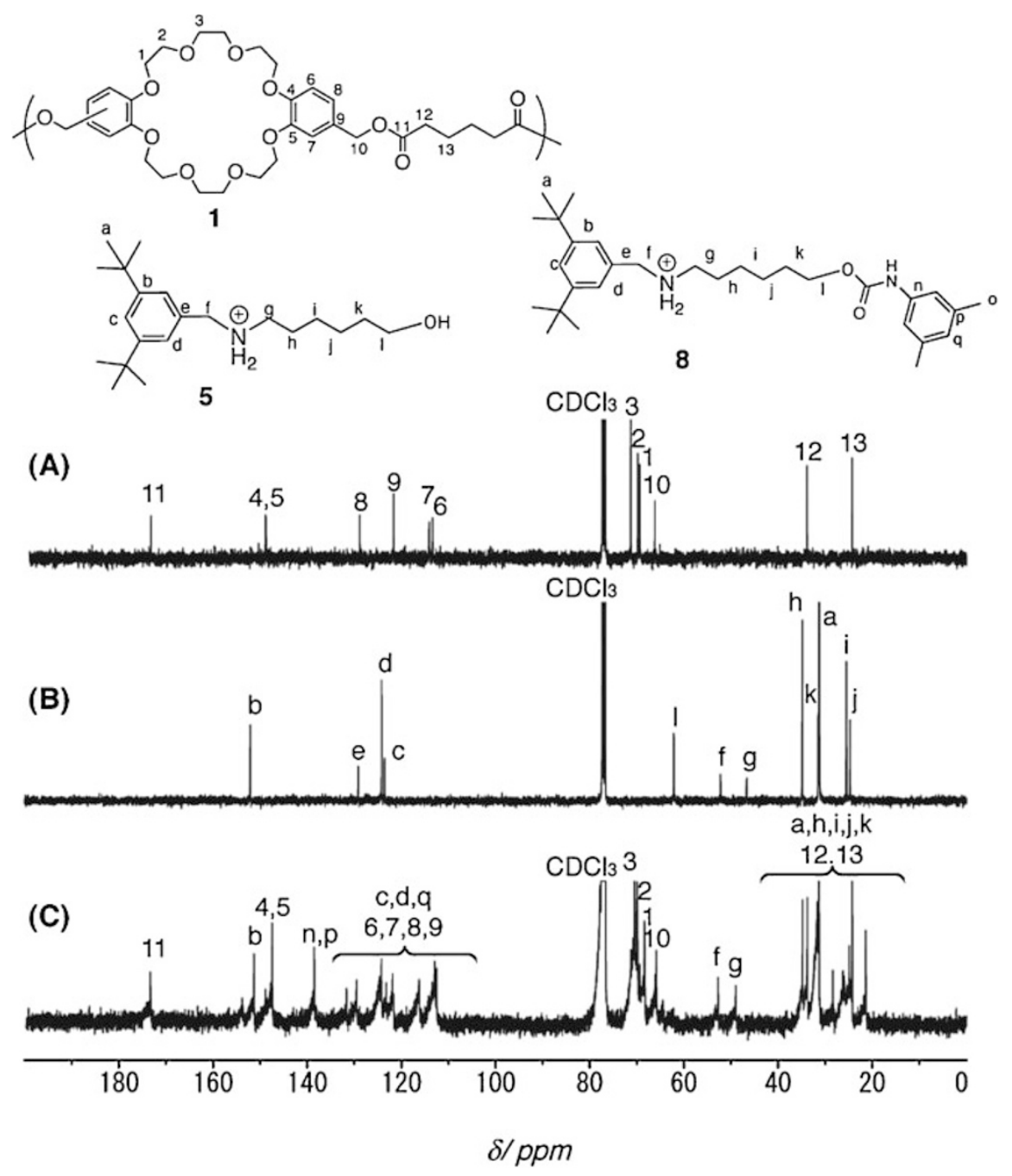

Figure 5. ${ }^{13} \mathrm{C}$ NMR spectra of (A) wheel 3, (B) axle 5 and (C) polyrotaxane 8.

peak at $1634 \mathrm{~cm}^{-1}$ identified as $\mathrm{C}=\mathrm{O}$ bond of the amide appeared. Whereas the ${ }^{1} \mathrm{H}$ NMR spectrum of 9 was broadened due to the presence of isomeric amide forms syn and anti in the axle in addition to the structural isomerism of the poly(crown ether) moiety, the acetyl proton signal $\mathbf{c}$ was confirmed around $2.1 \mathrm{ppm}$. The integral ratio suggested that the conversion of the ammonium group was 78\% (Figure 4 (B)). The higher field shift of the benzylic proton signal a (from $4.6 \mathrm{ppm}$ to $4.4 \mathrm{ppm}$ ) indicated the occurrence of the $\mathrm{N}$-acetylation which guaranteed the sliding motion of the axle or wheel.

From the GPC analysis, $M_{\mathrm{w}}$ and $M_{\mathrm{n}}$ of 9 (rotaxanated ratio $99 \%, N$-acetylated ratio $78 \%$ ) were estimated as 6100 and 4400, respectively, while those of poly(crown ether) 3 were 4000 and 2400, respectively. Increase in molecular weight by the structural change from 3 to 9 was similarly confirmed by MS spectral analysis (MALDI-TOF-MS (dithranol). 3: peak range, $\mathrm{m} / z$ 1000-5000, center peak $\mathrm{m} / z$ 3600; 9: peak range $m / z$ 3000-7000, center peak $m / z$ 5300). These results also indicate the formation of a main chain-type poly- rotaxane (B), being in accordance with the ${ }^{1} \mathrm{H}$ NMR and IR spectroscopic analyses mentioned above.

\section{Polyrotaxane network}

As a utilization of intermediate polypseudorotaxane 7 used in the approach to the main chain-type polyrotaxane (B), the derivation of 7 to polyrotaxane network was carried out. We previously succeeded in preparing novel polyrotaxane network by connecting poly(crown ether)s by rotaxane crosslinks via reversible SS bond cleavage of a dumbbell-shaped disulfidic axle component. ${ }^{15}$ Polypseudorotaxane 7 obtained in this work seemed a promising candidate precursor for a new type of polyrotaxane network, because of the quantitative conversion of $\mathbf{7}$ to polyrotaxane $\mathbf{8}$ or 9. The reaction of 7 prepared in situ $(82 \%$ of the rotaxanated ratio) with 4,4'-methylenebis(phenyl isocyanate) (MDI) in the presence of di(n-butyl)tindilaurate at $25^{\circ} \mathrm{C}$ for $16 \mathrm{~h}$ in chloroform afforded the corresponding polyrotaxane network $\mathbf{1 0}$ as a transparent gel (Scheme 6). Although the gelation proceeded within $4 \mathrm{~h}$ when the concentration of 7 was high 


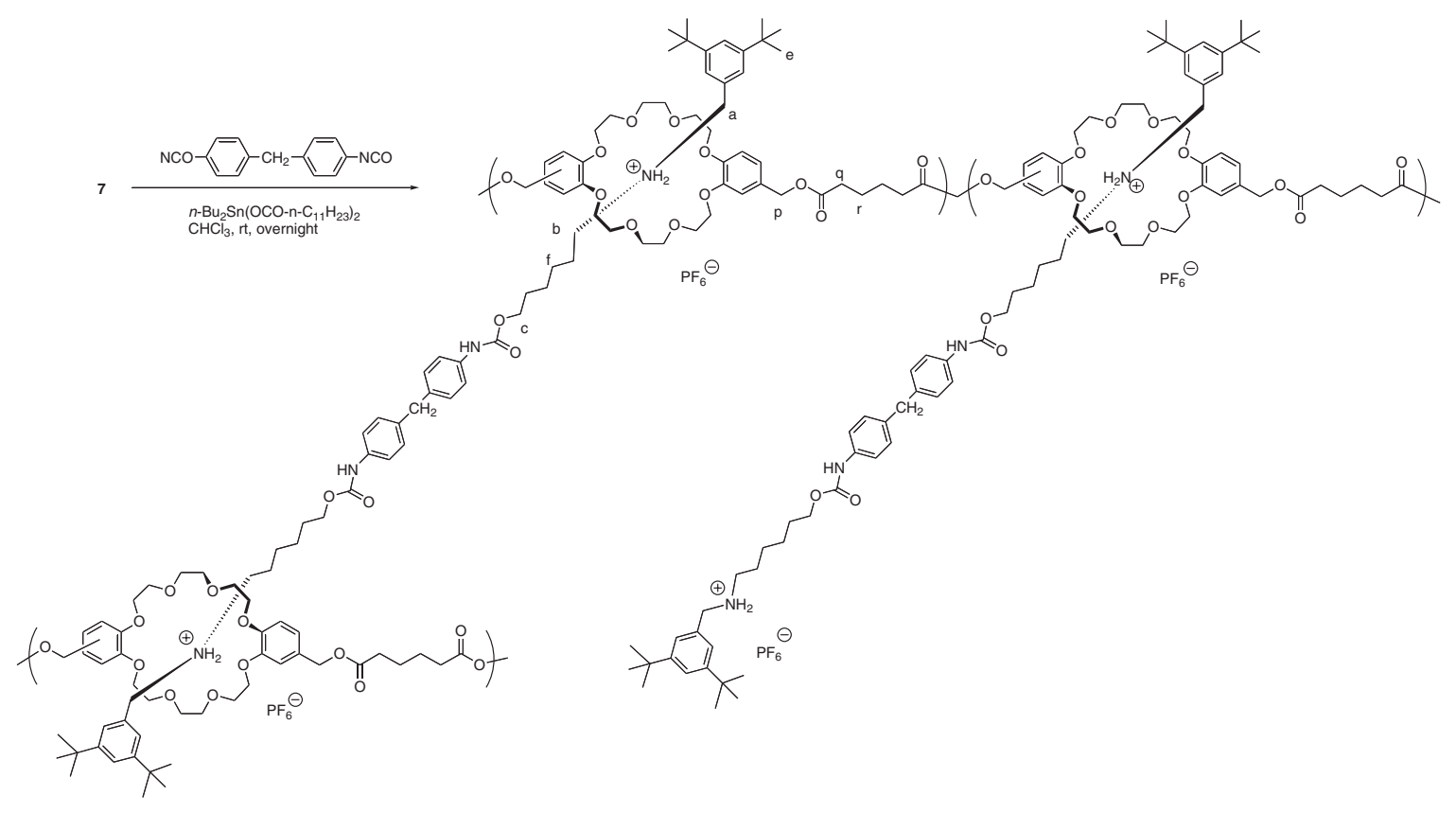

Scheme 6.

$(0.65 \mathrm{M})$, no gelation took place at $0.20 \mathrm{M}$ even for $16 \mathrm{~h}$. The gel obtained was subjected to repeated washing three times with chloroform and methanol to give colorless solid as polyrotaxane network $\mathbf{1 0}$ in 96\% yield. Most of soluble chemical substances such as unreacted MDI and the catalyst as well as ammonium salt 5 seemed to disappear from the product via this thorough washing process, since the gel displayed the prompt swelling in polar solvents such as acetone which probably suggested the low degree of crosslinking.

${ }^{1} \mathrm{H}$ NMR spectrum of the gel swollen in acetone- $\mathrm{d}_{6}$ is shown in Figure 6 which is relatively clear even for the crosslinked one. ${ }^{1} \mathrm{H}$ NMR spectrum of $\mathbf{6}$ is added for comparison. Typical signal $\mathbf{a}$ as an index for the complex formation or the rotaxane structure formation was actually observed around $4.6 \mathrm{ppm}$. From the integral ratio of signals $\mathbf{a}$ or $\mathbf{f}$ and $\mathbf{q}$, the degree of rotaxanation was roughly calculated to be $c a$. $30 \%$. In addition to the fact that a soft gel when swollen in organic solvents such as DMSO was formed, it would be concluded that the degree of crosslinking in $\mathbf{1 0}$ is low, although detailed crosslinked ratio is not clear at present time.

The swelling behavior was investigated in several typical organic solvents for $3 \mathrm{~d}$ at $30^{\circ} \mathrm{C}$. The degree of swelling (= ([weight of swelled gel] - [weight of dried gel])/[weight of dried gel] $\times 100$ ) is summarized in Table III. Crosslinked polymer $\mathbf{1 0}$ was well swollen in DMSO of which degree of swelling reached $9800 \%$, while that in methanol was $420 \%$. The high degree of swelling in DMSO can be attributed to both the ionic structure and the low degree of crosslinking of 10. Thus, the present synthetic method using polypseudorotaxane simply afforded the polyrotaxane network in high yield.

\section{CONCLUSION}

This work has demonstrated the synthesis of a main chain-type polyrotaxane (B) by end-capping of the axle terminal of polypseudorotaxane 7 with a bulky aromatic isocyanate. The pseudorotaxanation was studied in detail in the formation of 7. The complete pseudorotaxanation (>99\%) was achieved, while the incorporation ratio of the axle moiety was finely controllable. Polypseudorotaxane 7 was utilized for the preparation of a new type of polyrotaxane network: the reaction of 7 with diisocyanate MDI which combines terminal $\mathrm{OH}$ group of the axle of $\mathbf{7}$ yielded a gelled materials 10. The gel was highly swollen in polar solvent such as DMSO to give transparent insoluble material. ${ }^{1} \mathrm{H}$ NMR spectrum of $\mathbf{1 0}$ indicated the formation of the rotaxane structure, although the degree of crosslink was low. The present synthetic protocol for the main chain-type polyrotaxane (B) is efficient and convenient, whereas polypseudorotaxane as an intermediate in the preparation of polyrotaxane can be a useful precursor for polyrotaxane networks, giving some insights into functionalized network polymers. ${ }^{23}$

Acknowledgment. This work was supported by the Grant-in-Aid for Scientific Research on Priority Area (Area No. 446 and 459) from the Ministry of Education, Culture, Sports, Science and Technology (MEXT), Japan (No. 18039010 and 18064008). 


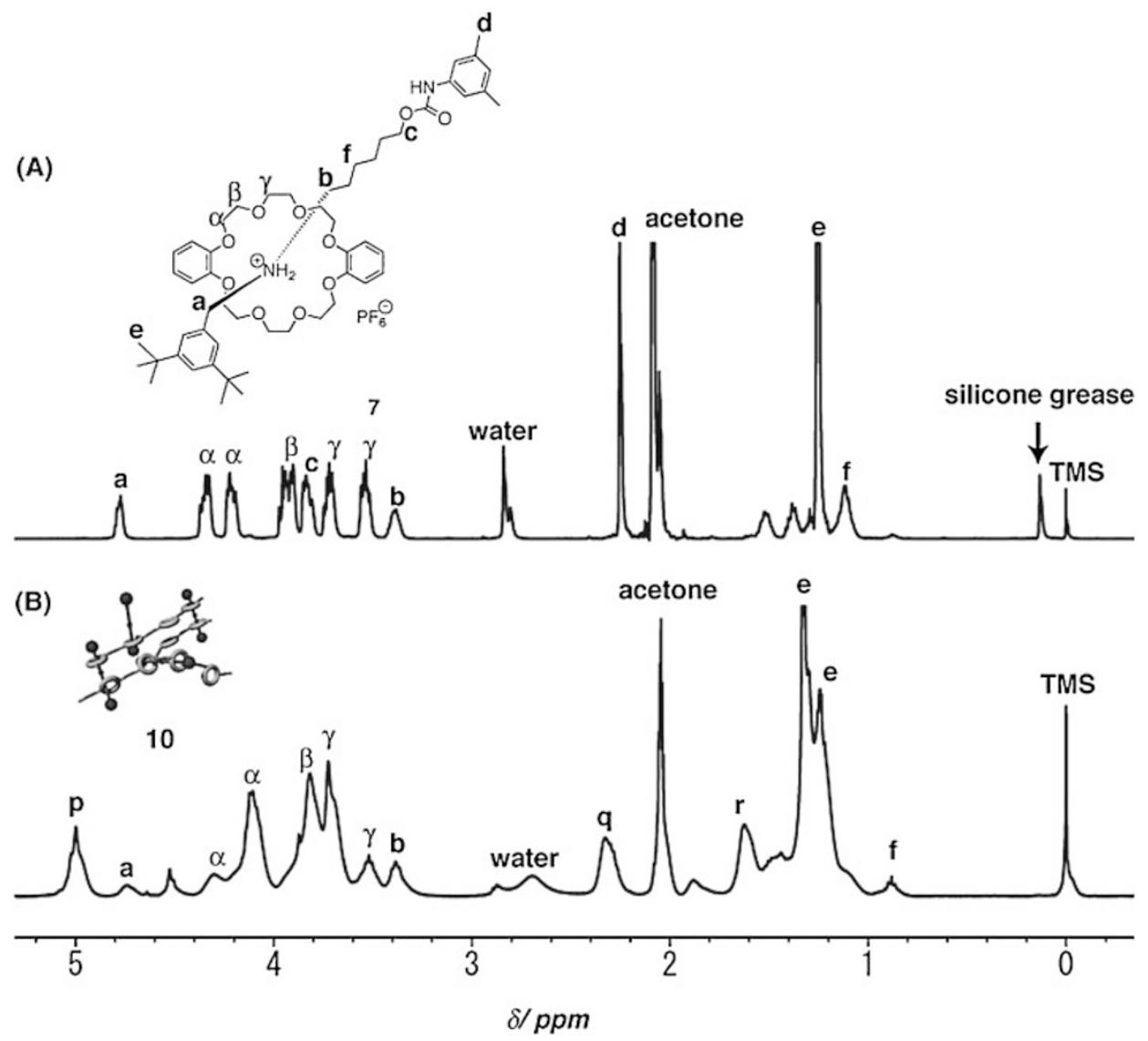

Figure 6. ${ }^{1} \mathrm{H}$ NMR spectra of (A) 7 and (B) 10 (400 MHz, $298 \mathrm{~K}$, acetone- $\left.d_{6}\right)$.

Table III. Swelling behavior of $\mathbf{1 0}^{\mathrm{a}}$

\begin{tabular}{cc}
\hline solvent & degree of swelling/\% \\
\hline methanol & 420 \\
chloroform & 140 \\
DMSO & 9800 \\
acetonitrile & 3300 \\
DMF & 2800 \\
Acetone & 1400 \\
\hline
\end{tabular}

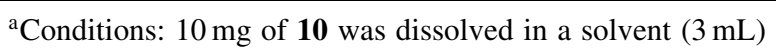
and the mixture was allowed to stand at $30^{\circ} \mathrm{C}$ for $3 \mathrm{~d}$.

\section{REFERENCES}

1. a) A. Harada, J. Li, and M. Kamachi, Nature, 356, 325 (1992).

b) A. Harada, J. Li, and M. Kamachi, J. Am. Chem. Soc., 116, 3192 (1994).

2. a) "Molecular Catenanes, Rotaxanes and Knots," J. P. Sauvage and C. Dietrich-Buchecker, Ed., Willy-VCH, Weinheim, 1999, p 277.

b) F. M. Raymo and J. F. Stoddart, "Supramolecular Polymers," A. Cifferi, Ed., Marcel Dekker, 2000, p 323.

c) T. Takata, N. Kihara, and Y. Furusho, Adv. Polym. Sci., 171, 1 (2004).

d) F. Huang and H. W. Gibson, Prog. Polym. Sci., 30, 982
(2005).

e) F. Huang and H. W. Gibson, Prog. Polym. Sci., 30, 982 (2005).

f) G. Wenz, B. Han, and A. Müller, Chem. Rev., 106, 782 (2006).

g) T. Takata, Polym. J., 38, 1 (2006).

3. a) C. Gong, T. E. Glass, and H. W. Gibson, Macromolecules, 31, 308 (1998).

b) K. Nagapudi, J. Hunt, C. Shepherd, J. Baker, and H. W. Beckham, Macromol. Chem. Phys., 200, 2541 (1999).

c) H. W. Gibson, P. T. Engen, and S. Lee, Polymer, 40, 1823 (1999).

d) I. Yamaguchi, K. Miya, K. Osakada, and T. Yamamoto, Polym. Bull., 44, 247 (2000).

e) N. Kihara, K. Hinoue, and T. Takata, Macromolecules, 38, 223 (2005).

f) X. Wang, H. Kim, Y. Fujita, A. Sudo, H. Nishida, and T. Endo, Macromolecules, 39, 1046 (2006).

g) R. Liu, A. Harada, and T. Takata, Polym. J., 39, 21 (2007).

h) R. Liu, N. Kihara, A. Harada, and T. Takata, J. Polym. Sci., Polym. Chem., 45, 1571 (2007).

i) H. Hirose, H. Sano, G. Mizutani, M. Eguchi, T. Ooya, and N. Yui, Polym. J., 30, 1093 (2006).

4. a) J. Jeromin and H. Ritter, Macromolecules, 32, 5236 (1999).

b) T. Takata, H. Kawasaki, S. Asai, N. Kihara, and Y. Furusho, Chem. Lett., 111 (1999).

c) I. Yamaguchi, K. Osakada, and T. Yamamoto, Macro- 
molecules, 33, 2315 (2000).

d) I. Yamaguchi, K. Osakada, and T. Yamamoto, Macromolecules, 33, 2315 (2000).

e) T. Takata, H. Kawasaki, N. Kihara, and Y. Furusho, Macromolecures, 34, 5499 (2001).

5. T. Oku, Y. Furusho, and T. Takata, J. Polym. Sci. Polym. Chemm., 41, 119 (2003).

6. Y. Sohgawa, H. Fujimori, Y. Furusho, N. Kihara, and T. Takata, Chem. Lett., 774 (2001).

7. J. Cantrill, G. J. Youn, and J. F. Stoddart, J. Org. Chem., 66, 6857 (2001).

8. T. Arai and T. Takata, Chem. Lett., 36, 418 (2007).

9. a) M. Kidowaki, C. Zhao, T. Kataoka, and K. Ito, Chem. Commun., 4102 (2006).

b) T. Kataoka, M. Kidowaki, C. Zhao, H. Minamikawa, T. Shimizu, and K. Ito, J. Phys. Chem. B, 110, 24377 (2006).

10. a) Y. Okumura and K. Ito, Adv, Mater., 13, 485 (2001).

b) K. Ito, Polym. J., 39, 489 (2007).

11. a) T. Karino, Y. Okuyama, K. Ito, and M. Shibayama, Macromolecules, 37, 6177 (2004).

b) T. Karino, Y. Okumura, C. Zhao, T. Kataoka, K. Ito, and M. Shibayama, Macromolecules, 38, 6161 (2005).

12. C. Zhao, Y. Domon, Y. Okuyama, S. Okabe, M. Shibayama, and K. Ito, J. Phys: Condes. Matter, 17, S2841 (2005).

13. C. Gong and H. W. Gibson, Angew. Chem., Int. Ed., 37, 310 (1998).

14. C. Gong and H. W. Gibson, J. Am. Chem. Soc., 119, 8585 (1997).

15. T. Oku, Y. Furusho, and T. Takata, Angew. Chem., Int. Ed., 43, 966 (2004).

16. T. Takata and H. Otsuka, Yuki Gosei Kagaku Kyoukaishi
(J. Syn. Org. Chem., Jpn.), 64, 194 (2006).

17. T. Takata, Y. Kohsaka, and G. Konishi, Chem. Lett., 36, 292 (2007).

18. Y. Furusho, H. Sasabe, D. Natsui, K. Murakawa, T. Takata, and T. Harada, Bull. Chem. Soc. Jpn., 77, 179 (2004).

19. Y. Tachibana, N. Kihara, and T. Takata, J. Am. Chem. Soc., 126, 3438 (2004).

20. N. Kihara and T. Takata, Yuki Gosei Kagaku Kyoukaishi (J. Syn. Org. Chem., Jpn.), 59, 206 (2001).

21. Similar figure to Figure 3 has already been reported in the previous paper. ${ }^{17}$ Since the quality of the spectra (iii) and (v) had not been sufficiently high, we again showed these spectra in the present Figure 3 to contribute to easy understanding.

22. a) H. Kawasaki, N. Kihara, and T. Takata, Chem. Lett., 28, 1015 (1999).

b) Y. Furusho, T. Oku, T. Hasegawa, A. Tsuboi, N. Kihara, and T. Takata, Chem. Eur. J., 9, 2895 (2003).

c) Y. Tachibana, H. Kawasaki, N. Kihara, and T. Takata, J. Org. Chem., 71, 5093 (2006).

23. a) T. Endo, T. Suzuki, F. Sanda, and T. Takata, Macromolecules, 29, 3315 (1996).

b) H. K. Kim, X. S. Wang, Y. Fujita, A. Sudo, H. Nishida, M. Fujii, and T. Endo, Macromol. Rapid Commun., 26, 1032 (2005).

c) H. J. Kwon, Y. Osada, and J. P. Gong, Polym. J., 38, 1211 (2006).

d) H. Okamura, K. Shin, and M. Shirai, Polym. J., 38, 1237 (2006).

e) T. Kimura, Y. Nakamoto, and G. Konishi, Polym. J., 38, 606 (2006). 